\title{
Identification of small molecules that inhibit the histone chaperone Asf1 and its chromatin function
}

\author{
Ja-Hwan Seol ${ }^{1,+, \#}$, Tae-Yang Song ${ }^{1, \#}$, Se Eun $\mathrm{Oh}^{2}$, Chanhee Jo ${ }^{1}$, Ahreum Choi ${ }^{1}$, Byungho Kim ${ }^{1}$, Jinyoung Park ${ }^{1}$, Suji Hong ${ }^{1}$, \\ Ilrang Song ${ }^{1}$, Kwan Young Jung ${ }^{1}$, Jae-Hyun Yang ${ }^{1, \neq}$, Hwangseo Park ${ }^{3}$, Jin-Hyun Ahn ${ }^{2}$, Jeung-Whan Han ${ }^{1}$ E Eun-Jung Cho ${ }^{1, *}$ \\ ${ }^{1}$ School of Pharmacy, Sungkyunkwan University, Suwon $16419,{ }^{2}$ Department of Molecular Cell Biology, Sungkyunkwan University School \\ of Medicine, Suwon 16419, ${ }^{3}$ Department of Bioscience and Biotechnology, Sejong University, Seoul 05006, Korea
}

The eukaryotic genome is packed into chromatin, which is important for the genomic integrity and gene regulation. Chromatin structures are maintained through assembly and disassembly of nucleosomes catalyzed by histone chaperones. Asf1 (anti-silencing function 1) is a highly conserved histone chaperone that mediates histone transfer on/off DNA and promotes histone $\mathrm{H} 3$ lysine 56 acetylation at globular core domain of histone H3. To elucidate the role of Asf1 in the modulation of chromatin structure, we screened and identified small molecules that inhibit Asf1 and H3K56 acetylation without affecting other histone modifications. These pyrimidine2,4,6-trione derivative molecules inhibited the nucleosome assembly mediated by Asf1 in vitro, and reduced the H3K56 acetylation in HeLa cells. Furthermore, production of HSV viral particles was reduced by these compounds. As Asf1 is implicated in genome integrity, cell proliferation, and cancer, current Asf1 inhibitor molecules may offer an opportunity for the therapeutic development for treatment of diseases. [BMB Reports 2015; 48(12): 685-690]

\section{INTRODUCTION}

In eukaryotic cells, genomic DNA forms a highly ordered structure called chromatin, which is composed of nucleosomes. The nucleosome core is composed of $147 \mathrm{bp}$ of DNA wrapped around the histone octamer containing two copies each of histones $\mathrm{H} 2 \mathrm{~A}, \mathrm{H} 2 \mathrm{~B}, \mathrm{H} 3$ and $\mathrm{H} 4$ (1). Chromatin structure and stability largely affect the gene expression and genome integrity.

${ }^{*}$ Corresponding author. Tel: +82-31-290-7781; Fax: +82-31-2928800; E-mail: echo@skku.edu

${ }^{\dagger}$ Current address: UT health science center at San Antonio, USA.

${ }^{\ddagger}$ Current address: Harvard Medical School, USA.

${ }^{\text {\#}}$ These authors contributed equally to this work.

http://dx.doi.org/10.5483/BMBRep.2015.48.12.063

Received 6 April 2015, Revised 4 May 2015, Accepted 8 June 2015

Keywords: Asf1, Epigenetic Regulation, Histone acetylation, Histone chaperone, Histone $\mathrm{H} 3$
Chromatin remodeling factors have an effect on the chromatin states, and controls the access of other factors to DNA to regulate its transcription, DNA replication, and DNA repair through covalent modification of histones or nucleosome assembly/disassembly in the choice of various histones (2).

When chromatin is not regulated correctly due to dysfunction of chromatin remodeling factors, many diseases occur, including several types of cancers. In recent years, there has been increasing interest in developing small molecules targeting the chromatin remodeling factors, especially histone modifying enzymes. Inhibitors of histone deacetylase complex (HDACi; SAHA, MS-275), histone demethylase (HDMi; GSK-J1), histone methyltransferase (HMTi; BIX-01294), and DNA methyltrasferase (DNMTi; 5-Azacytidine, Hydralazine) have been shown to possess anticancer activity, and are further being investigated for clinical therapy for a range of diseases (3-5). However, far too little attention has been paid to histone chaperones as targets of epigenetic therapy.

Histone chaperones, in addition to simple mediation of nucleosome dynamics, modulate most aspects of chromatin functions, directly or indirectly, through assistance of histone modification (6). Asf1, originally identified in budding yeasts with its impact on heterochromatin silencing, is the most conserved histone $\mathrm{H} 3 / \mathrm{H} 4$ chaperone protein from yeast to humans, and has been implicated in multiple functions in chromatin, including transcription, replication, and repair. Asf1 contributes to chromatin functions by delivering histone $\mathrm{H} 3 / \mathrm{H} 4$ onto DNA by coupling with other chaperones, such as CAF1 for nucleosome assembly during DNA replication, or HIRA complex for nucleosomes required during replication-independent chromatin formation such as transcription and senescence $(6,7)$. Asf1 is also an essential cofactor for histone acetylation on some residues of histone $\mathrm{H} 3 / \mathrm{H} 4$. The best-known ASf1-dependent acetylation target site is $\mathrm{H} 3 \mathrm{~K} 56$ in both budding yeast (8-10) and metazoans (11). Yeast Asf1 forms a complex with a fungal specific histone acetyl transferase (HAT), Rtt109, to promote H3K56 acetylation (12). $K_{\text {cat }}$ of Rtt109 is increased by about 100 -fold by Asf1. In metazoans, CBP/p300 is the corresponding HAT that acts with Asf1a isoform to mediate H3K56 acetylation (9). H3K56 acetylation in mammals is implicated in DNA replication, genome stability, stem cell pluripotency, and

ISSN: 1976-670X (electronic edition)

Copyright (C) 2015 by the The Korean Society for Biochemistry and Molecular Biology

(c) This is an open-access article distributed under the terms of the Creative Commons Attribution Non-Commercial License (http://creativecommons.org/licenses/by-nc/4.0) which permits unrestricted non-commercial use, distribution, and reproduction in any medium, provided the original work is properly cited. 


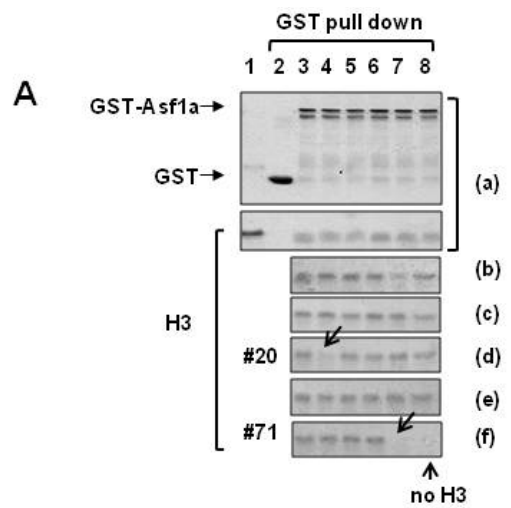

B
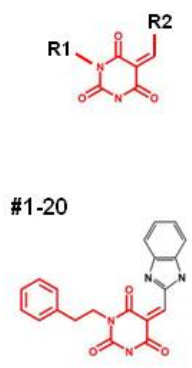

\#2-09

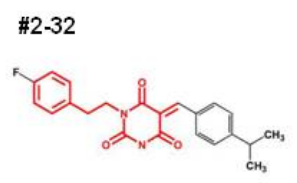

\#2-03

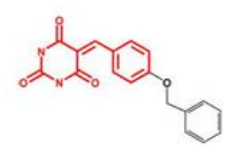

\#2-33

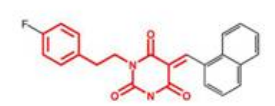

\#2-05

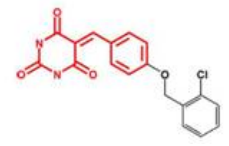

$\# 1-71$

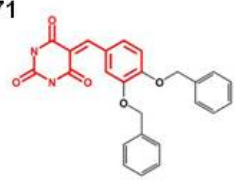

Fig. 1. Screening of small molecule inhibitors for human Asf 1 and histone $\mathrm{H} 3$ interaction. GST-human Asf1a was incubated with $\mathrm{H} 3$ in the presence of potential small molecule inhibitors, as described in Materials and Methods. The H3 binding was determined by PAGE, followed by immunoblotting assay. (A) One of the representative experiments that were performed for initial screening identified two potential inhibitors (compound \#1-20 and \#1-71 in a set of (d) and (f), respectively). Assay (a) lane1; H3 input, lanes 2; pull down with GST protein as a control. lanes 3-8; GST-Asf1a on glutathione-agarose beads. Reactions of lanes 2-8 received $\mathrm{H} 3$ proteins. Only $\mathrm{H} 3 \mathrm{lev}$ els are shown in (b-f) panels. (B) PYT (pyrimidine-2,4,6-trione) compounds in which R1 and R2 represent substituted groups. Structures of Asf1 inhibitors identified in the $1 \mathrm{st}$ round of screening: \#1-20 [(Z)-5-((1H-benzo[d]imidazol-2-yl) methylene)-1-phenethylpyrimidine2,4,6(1H,3H,5H)-trione] and \#1-71 [5-(3, 4-bis (benzyloxy)benzylidene)pyrimidine-2,4,6(1H,3H,5H)-trione]. (C) Six derivatives (\#2-32, \#2-33, \#2-03, \#2-05, \#2-09, \#2-19) identified from the 2nd round of screening show similar structural motif. cancers (11-16). However, the mechanism by which Asf1 and $\mathrm{H} 3 \mathrm{~K} 56$ are functionally combined in these cellular processes is not clear, except that the loss of $\mathrm{H} 3 \mathrm{~K} 56$ acetylation due to $\mathrm{H} 3$ binding defective mutation of Asf1 (V94R) indicates that the $\mathrm{H} 3$ binding of Asf1 is critical for $\mathrm{H} 3 \mathrm{~K} 56$ acetylation (9).

Chromatin needs to be highly dynamic to mediate appropriate regulation of gene expression and maintenance of genome integrity. This provoked considerable pharmaceutical interests for the development of small molecule inhibitors against various chromatin remodeling factors, mostly targeting covalent modification of histones or DNA. In this study, we sought to modulate chromatin by targeting the nucleosome assembly/disassembly pathway. For this purpose, we tried to find small molecules that inhibit Asf1's histone chaperoning activity, and focused to determine whether they could affect chromatin functions contributed by Asf1.

\section{RESULTS AND DISCUSSION}

\section{Screening of Asf1 inhibitor compounds}

To identify small molecules that interfere with the chromatin function of Asf1, medicinal chemistry initially screened the chemical compound library from InterBioScreen for molecules that would have an inhibitory effect on Asf1-histone $\mathrm{H} 3 / \mathrm{H} 4$ interaction, based on the crystal structure of Asf $1 / \mathrm{H} 3 / \mathrm{H} 4$ complex $(17,18)$. From a total of 260,000 compounds screened,
151 small molecules were identifies as probable inhibitors. These candidates were evaluated individually by the binding assay (as described in Materials and Methods) to see whether they had an effect on the interaction between GST-Asf1a and $\mathrm{H} 3$ in vitro (Fig. 1A). Two compounds (compounds \#1-20 and $\# 1-71$ ) had an inhibitory effect on Asf1/H3 binding (Fig. 1B). These compounds were pyrimidine-2,4,6-trione (PYT) derivatives with a substitution group at $\mathrm{R} 2(\# 1-71)$ and an additional phenethyl group at R1 (\#1-20). A series of PYT derivatives have previously been identified as matrix metalloproteinase (MMP) inhibitors, PPAR $\gamma$ agonists, or efficient drug candidates for a neurodegenerative disease such as Amyotrophic lateral sclerosis (ALS); however, they have never been studied as histone chaperone inhibitors (19-21). According to the distinct structural motif, 49 relevant derivatives were selected from the library and tested in the in vitro binding assay. This gave us further 6 additional hits, as shown in Fig. 1C. These compounds reduced the interaction between Asf1a and $\mathrm{H} 3$ in vitro in the range of $20-50 \mu \mathrm{M}$ concentration (Fig. 2, left panel). There are two closely related isoforms of Asf1 in humans, termed Asf1a and Asf1b. They have a highly conserved $\mathrm{N}$-terminal region (155 residues, $84 \%$ identical) that provides a binding platform for histone $\mathrm{H} 3 / \mathrm{H} 4$, which is sufficient for most of Asf1's functions $(6,22)$. Thus, it is likely that these compounds also have an ability to reduce the interaction between Asf1b and H3. As expected, these compounds affected 
the in vitro interaction between Asf1b and $\mathrm{H} 3$ (Fig. 2, right panel). Working concentrations of all compounds were in a similar range for both Asf1a and Asf1b, indicating that the small molecules might exert their inhibitory effects to the conserved structural features of the $\mathrm{N}$-terminal domains involved in $\mathrm{H} 3$ binding.

\section{Small molecule inhibitors reduced Asf1-mediated nucleosome assembly in vitro}

Asf1 is a histone chaperone; this activity can be measured in vitro as it generates various supercoiled DNA isomers in the presence of topoisomerase I through the incorporation of histone subunits onto naked DNA that are easily resolved on agarose gels. Addition of Asf1 to a relaxed plasmid DNA induced the appearance of fast-migrating supercoiled forms through nucleosome formation (Fig. 3, lane 5). To investigate whether the compounds that compromise the histone interaction of Asf1 also affect the nucleosome assembly activity, we carried out the in vitro nucleosome assembly assay, with GST-Asf1a and core histones in the presence of compounds. Each compound efficiently reduced the formation of supercoiled isoforms, indicating that they were able to inhibit nucleosome assembly mediated by Asf1a in vitro (Fig. 3A, compare lane 5 and lanes 6-11). As nucleosome assembly is the fundamental activity of Asf1 as a central $\mathrm{H} 3 / \mathrm{H} 4$ chaperone of both replication-dependent and replication-independent histone deposition pathways, our data provide the potential use of these compounds as useful molecules to understand Asf1's chromatin function.

\section{Asf1 inhibitory compounds reduced histone H3K56 acetylation in HeLa cells}

We next examined the inhibitory role of compounds by testing whether they can affect the level of H3K56 acetylation in cells. $\mathrm{H} 3 \mathrm{~K} 56$ acetylation is in part mediated by Asf1, when in combination with Rtt109 in yeast and p300/CBP in mammals. HeLa cells were first treated with siRNAs that target Asf1a or Asf1b, either individually or simultaneously. H3K56 acetylation decreased immediately within $24 \mathrm{hr}$, specifically when Asf1a is depleted by siRNA, confirming previous reports that

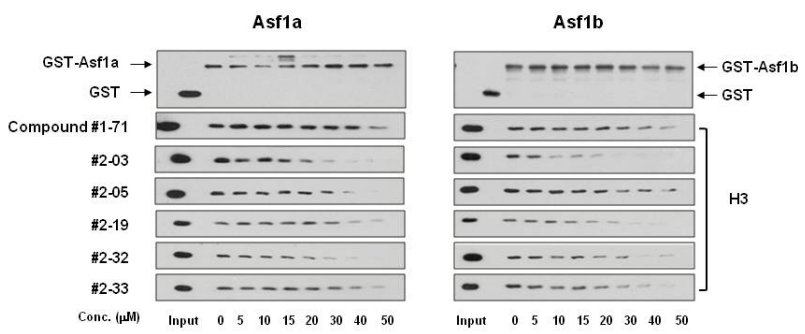

Fig. 2. Small molecules inhibit in vitro binding of Asf1a (left) and Asf1b (right) to histone $\mathrm{H} 3$ in a dose-dependent manner. GST pulldown and immunoblotting assay were performed, as described in Materials and Methods.
Asf1a, but not Asf1b, is required for acetylation of $\mathrm{H} 3 \mathrm{~K} 56$ in cells (11) (Fig. 4A, left panel). In addition, the reduction of K56 acetylation detected by Asf1a knock down at early time points was not observed after a $72 \mathrm{hr}$ incubation, regardless of sustained depletion of Asf1a (Fig. 4A, right panel). Since K56 acetylation is coupled to many aspects of DNA function, its level is often dynamically and reversibly changed depending on the cell cycle stages, recovery time after DNA damage, and the relative contribution of different HATs such as p300/CBP and hGcn5, and HDACs such as SIRT1/2 and HDAC1/2 (11, 15, 23, 24). In this study, as Asf1-dependent H3K56 acetylation could be detected at early time points, we treated cells with Asf1 inhibitor compounds for $24 \mathrm{hr}$. As shown in Fig. 4B, all compounds resulted in a substantial decrease of H3K56 acetylation to various extents (Fig. 4B). Whereas, other histone modifications that occur through Asf1-independent manner, such as H3K56 monomethylation, H3 K4 acetylation, H3 K4 dimethylation, were not altered. The inhibitory effect of the small molecules differed, probably due to their stability and different cell permeability properties. However, consistent with the requirement of direct binding between Asf1 and $\mathrm{H} 3$ for K56 acetylation, small molecules with activity of interfering Asf1/H3 interaction were effective in blocking the acetylation of $\mathrm{H} 3 \mathrm{~K} 56$ in cells tested.

\section{Asf1 inhibitor compounds reduced viral production}

Asf1 is critical in maintenance of cellular DNA, as it controls the histone flow for de novo nucleosome assembly on newly synthesized DNA during DNA replication. In addition, its histone deposition activity is required for efficient viral DNA replication. Asf1 plays an important role together with the cellular transcription factor HCF-1, in the production of herpes simplex virus (HSV)-1 and varicella zoster virus (VZV) $(25,26)$. Incorporation of histone H3 onto HSV-1 DNA and viral replication, are thus decreased by Asf1 depletion (27). If Asf1 is indeed the authentic target of the identified compounds, they

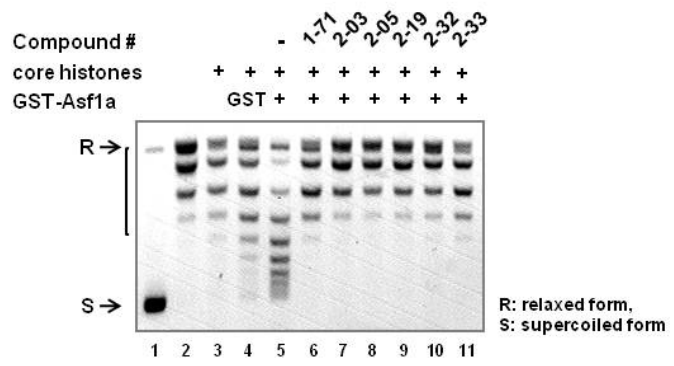

Fig. 3. Inhibition of Asf1a-mediated nucleosome assembly by small molecule inhibitors. DNA supercoiling induced by nucleosome assembly was analyzed in the presence of inhibitors (lane 6-11) at final concentration of $100 \mu \mathrm{M}$. GST (lane 4) or GST-Asf1a (lane 5-11), $0.5 \mu \mathrm{g}$ of each, was added to core histones $(0.33 \mu \mathrm{g}$, purified from HeLa cells) and relaxed plasmid DNA $(0.1 \mu \mathrm{g})$, as described in Materials and Methods. Migration of DNA isoforms are indicated. R: relaxed DNA; S: supercoiled DNA. 
A
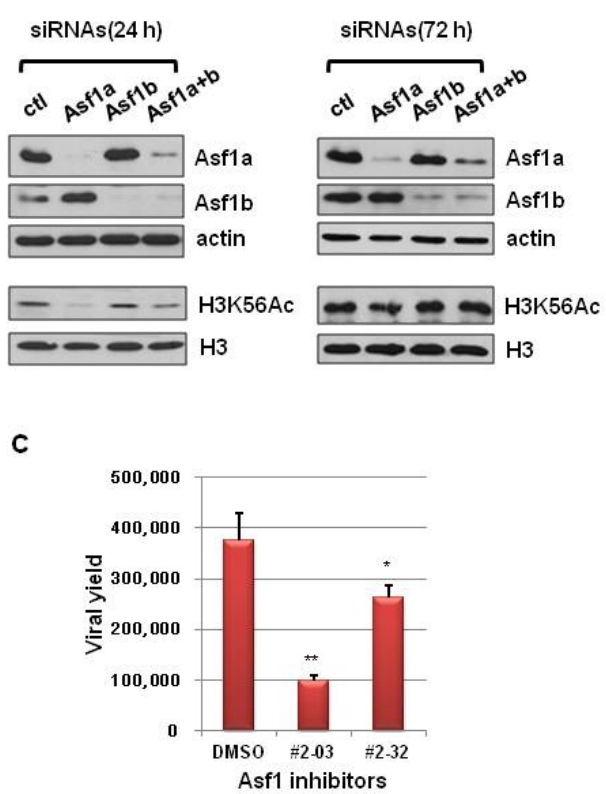

B

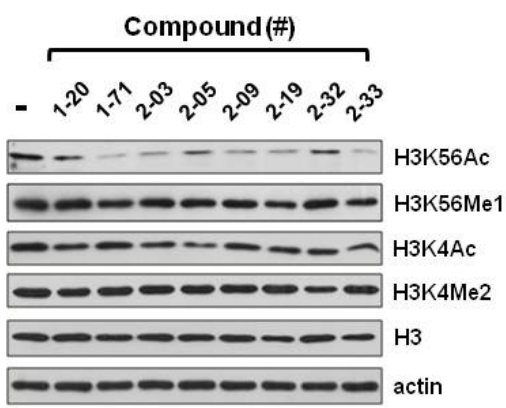

Fig. 4. In vivo function of chromatin mediated by Asf1 is affected by Asf1 inhibitors. (A) Role of Asf1 isomers in H3K56 acetylation. HeLa cells were treated with siRNAs (200 pmol) targeting Asf1a and Asf1b, either separately or simultaneously, for 24 hr (left panel) and 72 hr (right panel). Depletion of Asf1 and the effect on H3K56 acetylation was determined by immunoblotting assay with whole cell extracts and specific antibodies recognizing Asf1a, Asf1b, and H3K56Ac. (B) Asf1 inhibitors specifically reduced the level of H3K56 acetylation. HeLa cells were treated with each of the Asf1a inhibitors $(40 \mu \mathrm{M})$ for $24 \mathrm{hr}$ and whole cell lysate was prepared for immunoblotting, and probed with specific antibodies recognizing different histone modification. $\mathrm{H} 3$ and actin served as loading controls. (C) HSV-1 yield was decreased by treatment of \#2-03 and \#2-32. Vero cells treated with DMSO (control) or $80 \mu \mathrm{M}$ of each compound were infected with HSV-1 and viral yields in the culture supernatants were determined using plaque assay. Error bars represent the standard deviations of three independent experiments. Significance of difference was evaluated $(* P<0.05, * * P<0.005)$.

could possibly affect viral DNA synthesis also.

To investigate the effect of Asf1 inhibitor compounds on the viral DNA accumulation, we treated Vero host cells with DMSO control, or $80 \mu \mathrm{M}$ of compounds, \#2-03 and \#2-32, for $8 \mathrm{hr}$. As shown in Fig. 4C, quantitative analysis of viral DNA at $20 \mathrm{hr}$ post-infection showed significant reduction of viral DNAs from cells treated with \#2-03 or \#2-32, as compared to control, indicating that these compounds efficiently inhibit the activity of Asf1 required for viral DNA replication.

As a histone chaperone, Asf1 regulates most of the processes involving histones. First of all, it localizes at the active replication forks to mediate efficient chromatin duplication, where H3K56 acetylation is believed to be important for genome replication and integrity. Hence, rapidly proliferating cells such as cancer cells show increased H3K56 acetylation with increased levels of Asf1a/b, which makes Asf1 an attractive target for therapeutic intervention for cancer. Furthermore, H3K56 acetylation is a histone mark, more abundant in fungal species than in mammals, and proposed as a pharmacological target for the treatment of fungal infectious diseases caused by Candida albicans (28). In this regard, many efforts have been made to validate Asf1 as a biological target and to propose a new therapeutic approach. For example, a series of $\mathrm{N}$-acyl hydrazones have recently been reported as potential Asf1 inhibitors with moderate interference of Asf1- $\mathrm{H} 3 / \mathrm{H} 4$ binding (29). Here, we showed that Asf1 and its chromatin function can be interfered by PYT derivatives. Some PYT derivatives with diverse substitutions have been described as inhibitors of matrix metalloproteinase, and have antitumoral, antiangiogenic, and antimetastatic activities $(20,21)$. In this study, we have shown that PYT scaffold derivatives have an anti-Asf1 activity. As elevated expression of Asf1 is associated with high mitotic index and poor tumor grade with clinical relevance of disease outcome, targeting Asf1 will be a therapeutic opportunity for use in the treatment of cancer $(11,30)$. Although Asf1 inhibition activity of the current PYTs identified is not as strong as required and relatively high concentrations have been used for this study, they have a potential to work best with further optimization of molecular structure or in combination with other chromatin inhibitors, to be more potent epigenetic modulators having therapeutic possibilities. 


\section{MATERIALS AND METHODS}

\section{Preparation of GST-Asf1a}

Escherichia coli harboring pGEX-hAsf1a or pGEX-hAsf1b were induced by IPTG (Duchefa) and cells were harvested and resuspended in ice-cold PBS containing 1\% Triton X-100, $0.5 \mathrm{M}$ $\mathrm{NaCl}$, and protease/phosphatase inhibitors. Cells were lysed by sonication and whole cell extract was incubated with glutathione-agarose beads (Sigma-Aldrich). GST-proteins were eluted with elution buffer $[20 \mathrm{mM}$ Tris- $\mathrm{HCl}(\mathrm{pH} 7.5), 10 \%$ glycerol, $0.1 \%$ NP40, 0.35\% 2-mercaptoethanol, $20 \mathrm{mM}$ reduced glutathione].

\section{In vitro $\mathrm{H} 3$ binding assay}

GST-Asf1a or b were incubated with $20 \mu$ l glutathione-agarose beads for $30 \mathrm{~min}$ at room temperature. Beads were washed 4 times with $1 \mathrm{ml}$ of wash buffer, and then equilibrated with $1 \mathrm{ml}$ histone binding buffer [30 mM HEPES-KOH ( $\mathrm{pH} 7.5), 5 \%$ glycerol, $100 \mathrm{mM} \mathrm{NaCl}, 0.1 \%$ Triton X-100, $0.1 \mathrm{mM}$ EDTA, and 0.1 $\mathrm{mg} / \mathrm{ml} \mathrm{BSA]}$. Beads were incubated with $1.25 \mu \mathrm{g}$ of calf-thymus histone H3 (Roche 11034758 001) or $3 \mu \mathrm{g}$ of HeLa core histones (purified with Active Motif core histone purification kit; 40025), in the presence or absence of Asf1 inhibitor candidates (InterBioScreen Ltd, Russia), for $1 \mathrm{hr}$ at room temperature, with rotation. Beads were washed 4 times with $1 \mathrm{ml}$ of histone binding buffer. Histones co-precipitated with GST-Asf1 beads were analyzed by polyacrylamide gel electrophoresis (PAGE), followed by Coomassie staining or immunoblotting.

\section{Virtual screening}

The X-ray crystal structure of Asf1 (PDB entry: 2HUE) was selected as the receptor model in the virtual screening with docking simulations (17). The docking library for Asf1, comprising approximately 260,000 synthetic and natural compounds, was constructed from the latest version of the chemical database distributed by InterBioScreen Ltd. (http://www.ibscreen.com). We used the AutoDock program in the virtual screening because the excellence of its scoring function over those of the others had been demonstrated for various target proteins (31, 32). Finally, the compounds with the calculated binding free energy of lower than $-25 \mathrm{kcal} / \mathrm{mol}$ were selected as virtual hits and tested for their inhibitory activity against Asf1.

\section{In vitro nucleosome assembly assay}

$0.1 \mu \mathrm{g}$ of relaxed pBR322 plasmid DNA (Topogen) and $5 \mathrm{U}$ of wheat germ Topoisomerase I (Promega) were incubated for 30 min at $37^{\circ} \mathrm{C}$ in Topo I buffer [50 mM Tris- $\mathrm{HCl}(\mathrm{pH} 7.5), 50 \mathrm{mM}$ $\mathrm{NaCl}, 0.1 \mathrm{mM}$ EDTA, $1 \mathrm{mM}$ DTT, 20\% glycerol]. Meanwhile, $0.33 \mu \mathrm{g}$ of HeLa core histones and $0.5 \mu \mathrm{g}$ of purified GST or GST-hASF1a were incubated for $30 \mathrm{~min}$ at $37^{\circ} \mathrm{C}$ in nucleosome assembly buffer $[10 \mathrm{mM}$ Tris- $\mathrm{HCl}(\mathrm{pH} 7.5), 125 \mathrm{mM} \mathrm{NaCl}, 2$ $\mathrm{mM} \mathrm{MgCl} 2,0.5 \mathrm{mM}$ DTT. $0.1 \mathrm{mg} / \mathrm{ml} \mathrm{BSA}$ ], with or without the small molecule inhibitors. The two reaction mixtures were combined and further incubated for $1 \mathrm{hr}$ at $37^{\circ} \mathrm{C}$. Reaction was stop- ped by addition of $60 \mu \mathrm{l}$ of stop solution (20 mM EDTA, 1\% SDS, $200 \mu \mathrm{g} / \mathrm{ml}$ pronase) followed by incubation at $37^{\circ} \mathrm{C}$ for 30 min. Plasmids were purified with phenol-chloroform-isoamylalcohol extraction and precipitated with ethanol. DNA was analyzed on $1.2 \%$ agarose gel $\left(50 \mathrm{~V}, 12 \mathrm{hr}, 4^{\circ} \mathrm{C}\right)$, and visualized by ethidium bromide staining.

\section{siRNA treatment}

For RNA interference assays, cells were transfected with a control siRNA (AccuTarget ${ }^{\mathrm{TM}}$ Negative control siRNA, Bioneer) or siRNAs against Asf1a and Asf1b (ST Pharm, Korea). Transfection of siRNAs was performed with Lipofectamine 2000 (Invitrogen) according to the manufacturer's instructions. The sequences of siRNAs are as following; AAGUGAAGAAUACGAUCAAGUTT (si-Asf1a) and AACAACGAGUACCUCAACCCUTT (si-Asf1b).

\section{Western blot analysis}

For western blotting, cells were lysed in NETN lysis buffer [20 $\mathrm{mM}$ Tris- $\mathrm{HCl}(\mathrm{pH} 7.4), 150 \mathrm{mM} \mathrm{NaCl}, 0.5 \% \mathrm{NP}-40$, and inhibitors of proteases and phosphatases]. After 10 min incubation on ice, the cell lysate was recovered by centrifugation $(13,000$ rpm at $4^{\circ} \mathrm{C}$ ). Proteins were resolved by SDS-PAGE and subjected to immunoblotting with appropriate antibodies. Protein bands were visualized by ECL detection reagent (Abfrontier, Korea). Following antibodies were used in this study: anti-Asf1a (Cell Signaling), anti-Asf1b (Cell Signaling), anti-actin (Millipore), antiH3 (Abcam), anti-H3K56Ac (Active-motif), anti-H3K56Me1 (Activemotif), anti-H3K4Ac (Active-motif), anti-H3K4Me2 (Millipore).

\section{Virus experiment}

HSV-1 (strain KOS/tk12) was provided by Patricia G. Spear (Feinberg School of Medicine of Northwestern University, Chicago, IL, USA) (33). African green monkey kidney cells (Vero cells) were maintained and infected with HSV-1 according to standard protocols. Briefly, cells were treated with 80 $\mu \mathrm{M}$ of compounds or DMSO vehicle for $8 \mathrm{hr}$ before HSV-1 infection. Cells were infected with virus particles at a MOI (multiplicity of infection) of 0.2 in serum-free DMEM medium for $1 \mathrm{~h}$ at $37^{\circ} \mathrm{C}$ in $5 \% \mathrm{CO}_{2}$ chamber with rocking, after which serum-supplemented medium was added. Cells were further incubated for $20 \mathrm{hr}$ for determination of viral yield in the culture supernatants, using the plaque assay. For the plaque assay, Vero cells in a 6 -well plate $\left(1 \times 10^{6}\right.$ cells/well $)$ were infected with the serially diluted virus samples. After $1 \mathrm{hr}$ incubation, the culture medium was removed and $2 \mathrm{ml}$ of methylcellulose overlay was added to each well, and incubated for 3 days. The methylcellulose was then removed, and the cell monolayer was stained with $1 \%$ crystal violet in $50 \%$ ethanol for $20 \mathrm{~min}$. The cells were then washed with tap water and the numbers of plaque were counted.

\section{ACKNOWLEDGEMENTS}

This work was supported by the Mid-career Researcher Program 
(2013R1A2A2A01014702) and the Basic Science Research Program (2010-0028646) through the National Research Foundation of Korea grant funded by the Ministry of Education, Science and Technology to E.-J.C.

\section{REFERENCES}

1. Luger K, Mader AW, Richmond RK, Sargent DF and Richmond TJ (1997) Crystal structure of the nucleosome core particle at 2.8 A resolution. Nature 389, 251-260

2. Gardner KE, Allis CD and Strahl BD (2011) Operating on chromatin, a colorful language where context matters. J Mol Biol 409, 36-46

3. West AC and Johnstone RW (2014) New and emerging HDAC inhibitors for cancer treatment. J Clin Invest 124, 30-39

4. Lund K, Cole JJ, VanderKraats ND et al (2014) DNMT inhibitors reverse a specific signature of aberrant promoter DNA methylation and associated gene silencing in AML. Genome Biol 15, 406

5. Helin K and Dhanak D (2013) Chromatin proteins and modifications as drug targets. Nature 502, 480-488

6. Gurard-Levin ZA, Quivy JP and Almouzni G (2014) Histone chaperones: assisting histone traffic and nucleosome dynamics. Annu Rev Biochem 83, 487-517

7. Kim HJ, Seol JH, Han JW, Youn HD and Cho EJ (2007) Histone chaperones regulate histone exchange during transcription. EMBO J 26, 4467-4474

8. Driscoll R, Hudson A and Jackson SP (2007) Yeast Rtt109 promotes genome stability by acetylating histone $\mathrm{H} 3$ on lysine 56 . Science $315,649-652$

9. Recht J, Tsubota T, Tanny JC et al (2006) Histone chaperone Asf1 is required for histone $\mathrm{H} 3$ lysine 56 acetylation, a modification associated with $S$ phase in mitosis and meiosis. Proc Natl Acad Sci U S A 103, 6988-6993

10. Tsubota T, Berndsen CE, Erkmann JA et al (2007) Histone $\mathrm{H} 3-\mathrm{K} 56$ acetylation is catalyzed by histone chaperone-dependent complexes. Mol Cell 25, 703-712

11. Das C, Lucia MS, Hansen KC and Tyler JK (2009) CBP/ p300-mediated acetylation of histone H3 on lysine 56. Nature 459, 113-117

12. Han J, Zhou H, Horazdovsky B, Zhang K, Xu RM and Zhang Z (2007) Rtt109 acetylates histone H3 lysine 56 and functions in DNA replication. Science 315, 653-655

13. Tan $Y$, Xue $Y$, Song $C$ and Grunstein M (2013) Acetylated histone H3K56 interacts with Oct4 to promote mouse embryonic stem cell pluripotency. Proc Natl Acad Sci U S A 110, 11493-11498

14. Yuan J, Pu M, Zhang Z and Lou Z (2009) Histone H3-K56 acetylation is important for genomic stability in mammals. Cell Cycle 8, 1747-1753

15. Battu A, Ray A and Wani AA (2011) ASF1A and ATM regulate H3K56-mediated cell-cycle checkpoint recovery in response to UV irradiation. Nucleic Acids Res 39, 7931-7945

16. Gonzalez-Munoz E, Arboleda-Estudillo $\mathrm{Y}$, Otu $\mathrm{HH}$ and Cibelli JB (2014) Cell reprogramming. Histone chaperone ASF1A is required for maintenance of pluripotency and cellular reprogramming. Science 345, 822-825

17. English CM, Adkins MW, Carson JJ, Churchill ME and Tyler JK (2006) Structural basis for the histone chaperone activity of Asf1. Cell 127, 495-508

18. Agez M, Chen J, Guerois R et al (2007) Structure of the histone chaperone ASF1 bound to the histone H3 C-terminal helix and functional insights. Structure 15, 191-199

19. Sundriyal S, Viswanad B, Ramarao P, Chakraborti AK and Bharatam PV (2008) New PPARgamma ligands based on barbituric acid: virtual screening, synthesis and receptor binding studies. Bioorg Med Chem Lett 18, 4959-4962

20. Maquoi E, Sounni NE, Devy L et al (2004) Anti-invasive, antitumoral, and antiangiogenic efficacy of a pyrimidine-2,4, 6-trione derivative, an orally active and selective matrix metalloproteinases inhibitor. Clin Cancer Res 10, 4038-4047

21. Xia G, Benmohamed R, Kim J et al (2011) Pyrimidine-2,4, 6-trione derivatives and their inhibition of mutant SOD1dependent protein aggregation. Toward a treatment for amyotrophic lateral sclerosis. J Med Chem 54, 2409-2421

22. Song Y, Seol JH, Yang JH et al (2013) Dissecting the roles of the histone chaperones reveals the evolutionary conserved mechanism of transcription-coupled deposition of H3.3. Nucleic Acids Res 41, 5199-5209

23. Miller KM, Tjeertes JV, Coates J et al (2010) Human HDAC1 and HDAC2 function in the DNA-damage response to promote DNA nonhomologous end-joining. Nat Struct Mol Biol 17, 1144-1151

24. Tjeertes JV, Miller KM and Jackson SP (2009) Screen for DNA-damage-responsive histone modifications identifies H3K9AC and H3K56Ac in human cells. EMBO J 28, 18781889

25. Peng H, Nogueira ML, Vogel JL and Kristie TM (2010) Transcriptional coactivator HCF-1 couples the histone chaperone Asf1b to HSV-1 DNA replication components. Proc Natl Acad Sci U S A 107, 2461-2466

26. Ambagala AP, Bosma T, Ali MA et al (2009) Varicella- zoster virus immediate-early 63 protein interacts with human antisilencing function 1 protein and alters its ability to bind histones h3.1 and h3.3. J Virol 83, 200-209

27. Oh J, Ruskoski N and Fraser NW (2012) Chromatin assembly on herpes simplex virus 1 DNA early during a lytic infection is Asf1a dependent. J Virol 86, 12313-12321

28. Wurtele H, Tsao S, Lepine G et al (2010) Modulation of histone $\mathrm{H} 3$ lysine 56 acetylation as an antifungal therapeutic strategy. Nat Med 16, 774-780

29. Miknis GF, Stevens SJ, Smith LE, Ostrov DA and Churchill ME (2015) Development of novel Asf1-H3/H4 inhibitors. Bioorg Med Chem Lett 25, 963-968

30. Corpet A, De Koning L, Toedling J et al (2011) Asf1b, the necessary Asf1 isoform for proliferation, is predictive of outcome in breast cancer. EMBO J 30, 480-493

31. Morris GM, Green LG, Radic Z et al (2013) Automated docking with protein flexibility in the design of femtomolar "click chemistry" inhibitors of acetylcholinesterase. J Chem Inf Model 53, 898-906

32. Park H, Lee J and Lee S (2006) Critical assessment of the automated AutoDock as a new docking tool for virtual screening. Proteins 65, 549-554

33. Warner MS, Geraghty RJ, Martinez WM et al (1998) A cell surface protein with herpesvirus entry activity (HveB) confers susceptibility to infection by mutants of herpes simplex virus type 1 , herpes simplex virus type 2 , and pseudorabies virus. Virology 246, 179-189 